\title{
¿Cuál es el sentido de la historia?
}

\author{
JAVIER ALDAMA Pineido \\ Universidad Nacional Mayor de San Marcos
}

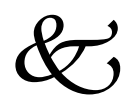

\begin{abstract}
Resumen
En este texto se hace un repaso de la constitución de la historia y la historiografía y del planteamiento de algunos filósofos (de Voltaire a Fukuryama) sobre este proceso constitutivo. El hilo conductor que sigue el texto pretende dar respuesta a la pregunta: ¿auál es el sentido de la historia? Hacia el final, el autor ensaya una respuesta a la pregunta planteada desde la perspectiva de los países periféricos.
\end{abstract}

Palabras claves: Historia, historiografía, finde la historia, Occidente.

1 ecía Hegel que la "Historia reúne en muestro idioma tanto el lado objetivo como el subjetivo y significa, de la misma manera, la historiam rerum gestarum como la res gestas. Ella significa todo lo acontecido, lo mismo que la historia relatada. Esta reunión de ambos significados debemos tomarla como algo más que una causalidad externa. Es de creer que el relato histórico nace simultáneamente con los acontecimientos y acciones históricas. Es una base común lo que los junta" (Hegel 1976: 81). Efectivamente, la historia como conjunto de acontecimientos debe diferenciarse de la historiografía o investigación histórica; sin embargo, esto no significa una separación tajante entre ambos aspectos. Ia historia, en su aspecto objetivo, se refiere a un tipo particular de acontecimientos que se relacionan entre sí y entre los cuales hay continuidad y coherencia; pero es cuando se forma el concepto, al comprenderse el movimiento de los 
acontecimientos (vid. Kahler 1966: 14) y, al sentido al que se dirigen, cuando nace la historia; esto es, cuando se descubre el aspecto subjetivo como indispensable.

La historia -en su lado objetivo- es indesligable de su narración, de su interpretación. Pero no solo se relata lo acontecido, sino que, en función del concepto adquirido, la historiografía va más allá de ser un simple espejo reflector y ella misma se hace parte de la historia dojetiva.

Consideramos que lo dicho amerita por lo menos un ejemplo, para lo cual nos vamos a servir de Karl Löwith (1973: 220) :

... sólo los judíos son un pueblo realmente histórico, constituido cano tal por la religión, mediante el acto de la revelación del Sinaí. De aquí que el pueblo judío pudb, y aun puede en verdad, entender religiosamente su historia y destino nacionales como una unidad político-religiosa. Ia ley etema que los griegos consideraron implícita en el movimiento regular del universo visible se manifestó a los judíos en las vicisitudes de su historia, que es una historia de intervenciones divinas, aunque en extremo irregulares. Dios llamó a Abrahám de Ur, sacó a Israel de Egipto, dio la ley en el Sinaí, elevó a David a la dignidad real, castigó a su pueblo, valiéndose de Asiria y de Babil lonia, y lo redimió por medio de Ciro el persa y, lo que es más asambroso, la firmeza de esta fe en un designio moral divino se elevó al máximo precisamente cuando toda evidencia empírica estaba contra ella. Cuando la potencia mundial de Asiria conquistó el cercano Este, los profetas vieron en la nuina material de Israel, no una prueba de la impotencia de Jahveh, sino una manifestación indirecta de su poder universal. Para Isaías, no fue Bel, sino Jehová el que triunfó en la caída de Judea. La misma Asiria no fue sino un instrumento en las manos del Dios de Israel y pudo ser descartada cuando el designio divino se hubo realizado.

Como puede notarse, no es el mero acontecer lo que da sentido a la historia hebrea, sino conceptos como el de un Dios único y omnipresente, o el concepto de la misión que tenían como pueblo elegido; estos conceptos dan coherencia al relato y establecen una interpretación a la que podemos considerar errónea, pero a la que no podemos negar presencia y fuerza, tanto en el pasado como en el presente.

A lo que se refiere la palabra historia en un primer momento es a una indagación física. El considerado padre de la historia, Herodoto, 
combinaba sus relatos de los acontecimientos en tierras extranjeras con geografía y etnografía. La historia era una especie de historiografía, sobre todo de historiografía política (Kahler 1966: 34-36). El sentido que en aquel entonces tenía esta historia era saber cómo se debía actuar y vivir en relación a un orden cósmico, no en función de una meta vinculada a la existencia humana. En quienes mejor se observa esta relación es en los estoicos, que buscaban "vivir según la naturaleza".

En la antigüedad, fue Polibio el primero en ver la realización de una historia universal: "Antes los hechos del mundo eran, por decirlo así, dispersos, ya que no se mantenían juntos por ninguna unidad de iniciativa... ; pero desde esta fecha [la Olimpiada 140, o sea, entre 220216 a.C. ] la historia se ha vuelto un toob orgánico [... ] , y los negocios de Italia y Libia se han trenzado con los de Grecia y Asia, y todos conducen a un fin" (citado en Kahler, 1966: 39) .

Esta historia universal se había hecho posible por el daminio del reino romano; además, polibio era consciente de haber descubierto el carácter orgánico y dinámico del proceso histórico: ... Así cbservo que, en tanto que varios autores se capan de guerras particulares y de ciertos asuntos a ellos vinculados, ninguno que yo sepa, ha intentado jamás indagar críticamente cuándo y cómo se dirigió a su fin (... ) No podemos confiar en percibir esto a través de las historias que tratan de asuntos particulares, camo tampoco adquirir de golpe una noción de la forma del mundo entero, de su disposición y orden, visitando por tumo las ciudades más famosas o, más bien, contemplando los respectivos planos de ellas. En verdad, aquel que supone que estudiando historias aisladas puede adquirir una idea bastante justa de la historia como un todo se parece mucho, en mi opinión, al que después de haber contemplado los miembros dispersos de un animal otrora viviente y bello se figura que es como si hubiese sido testigo ocular de tal criatura con todos sus movimientos y su gracia" .

Pero ni siquiera en Polibio se llega a concebir la historia como desarrollo de la humanidad. Entre los griegos, la historia es entelequia, presente que o se interpreta como decadencia a partir de una edad de oro mítica o se interpreta como consumación y convergencia de acontecimientos (como en Polibio) . 
La noción de la historia, como avance del hombre como tal, se origina con los judíos; con ellos la historia adquiere el sentido de propásito. El cristianismo toma este concepto pero lo vincula al Dioshombre y su mensaje. Con Pablo se establece además la posibilidad del divorcio entre lo natural y lo sobrenatural, separación que hará posible, más adelante, el planteamiento de una historia secular, es decir, de la historia modema, lo que aconteció precisamente cuando la historia vinculada a lo sobrenatural decae y la teología de la historia deja su lugar a la filosofía de la historia.

Ia interpretación secular de la historia se hace realidad en el siglo XVIII con la historiografía de la ilustración, que tiene como representante más notorio a Voltaire. Este movimiento adoptó una postura antirreligiosa y consideró a la Edad Media como la era del dominio de la casta sacerdotal y la superstición religiosa. El Medicevo es visto así como un período de barbarie e irracionalidad. Lo importante para un ilustrado es el despertar del espíritu modemo, el surgimiento de la iniciativa de industria y comercio, y el predominio del despotismo ilustrado; pero, en el fondo, su actitud es antihistórica, puesto que la aparición de este nuevo tiempo era para él poco menos que un milagro, ya que lo que había antes eran solo tinieblas.

La vida humana es considerada, en general, como un actuar ciego e irracional, aunque es pasible de convertirse en racional. Para Gibbon, por ejemplo, "la historia podría ser todo menos una prueba de la sabiduría humana" , y llega a concebir como fuerza motriz de la historia la misma irracionalidad humana. Condorcet, en cambio, "promete un futuro utópico, donde ya no habrá tiranos y esclavos, ni sacerdotes y engañados y donde la gente se comportará de un modo racional en el gozo de la vida y de la libertad, y en la busca de la dicha" (Collingwood 1965: 85).

Es de notar que durante la ilustración se establece la perspectiva "individualista" de interpretación de la historia, donde se piensa que algún o algunos individuos sobresalientes marcan el arso de la historia; de allí que Pascal ironice con aquello de "que si la nariz de Cleopatra hubiese sido más larga, la historia del mundo habría sido distinta".

A partir de Rousseau se empieza a considerar al pueblo como protagonista de la historia. Rousseau concibe la voluntad general del 
pueblo como siempre existente y actuante; la voluntad general es un pacto en el que cada individuo renuncia a su interés en favor de la colectividad, del bien común. El futuro es pensado, entonces, en función no ya de una élite ilustrada, sino de un pueblo ilustrado. Con la irnpoción del romanticismo se vuelve a valorar el pasado y a concebir la historia como progreso, como un desarrollo de la razón humana en el que las etapas pasadas conducen necesariamente al presente.

Kant, a fines del siglo XVIII, asume la perspectiva ilustrada y considera al pasado como dominio de la irracionalidad humana, pero también considera que hay un plan de la naturaleza que el hombre sigue sin darse cuenta. Este plan consiste en el desarrollo de la humanidad hasta lograr la plenitud de la libertad: el propósito de la naturaleza al dotar al hombre de razón es el desarrollo de su libertad moral. La naturaleza tiene como propósito el desarrollo de la esencia de cada una de sus creaturas; ahora bien, siendo la esencia del hombre su razón, el propósito de la naturaleza es el desarrollo de esta esencia, la razón, pero este plan sólo puede realizarse en la historia humana y no en una vida individual.

En la primera mitad del siglo XIX, Hegel se muestra como el típico filósofo determinista de la historia. Luego de Hegel, pensadores destacados asumirán el papel de herederos críticos de su fil losofía, como ocurre con Marx y Engels, o de apologistas tardíos como Fukuyama; pero también se presentarán críticas implacables y que no encontrarán nada positivo en la dialéctica hegeliana, como son Nietzsche y Popper. De todas maneras es inevitable referirse a Hegel si se habla del sentido de la historia o de filosofía de la historia.

Hegel, en sus conferencias sobre la historia (publicadas con el nombre de Fil losofía de la Historia) , presentará la historia universal como el proceso racional de una ruta necesaria del espíritu universal. Reconocerá como antecedente de su exposición la forma religiosa de la verdad, que considera al mundo gobemado por la providencia, pero Hegel no coloca a Dios en el "más allá", sino en la historia universal, en la que lo esencial es "el espíritu y la trayectoria de su desarrollo". A su vez, la esencia del espíritu está condicionada por la libertad; el espíritu no sale de sí, sino que se desarrolla como conciencia, como la simiente del árbol en la que están contenidas todas las futuras 
características de éste. Ell espíritu se identifica con el desarrollo de la conciencia humana y la conciencia de la libertad; así surge como un "en sí" , como un impulso interior, como necesidad, pero su misión es llegar a un estado de conciencia. Para esto, la libertad cuenta con ciertos medios que son, en primer lugar, las pasiones, las metas del interés particular y la satisfacción del egoísmo; como segundo elemento está la acción del hombre cuyo principio es la voluntad. En los actos del hombre surge la historia universal en cuanto va apareciendo algo distinto a lo que se desea y logra: los hombres persiguen sus intereses, pero realizan, a la vez, algo diferente que yace en el interior de sus acciones, aunque de esto no son conscientes ni está en sus propósitos.

Los hombres representativos o individuos históricos son aquellos "cuyas finalidades particulares contienen lo substancial, es decir, lo que es la voluntad del espíritu universal" ; su misión es subir el peldaño que guía hacia el futuro y convertirlo en su meta. Estos individuos históricos son "grandes hombres precisamente por haber deseado y realizado lo que era adecuado y necesario" . Los individuos no son sino medios para una finalidad superior, pero esto no significa que el individuo sea algo exterior y ajeno a la meta. El individuo, con su participación, hace posible la meta y se convierte en finalidad autónoma.

Hegel, además, pone en lugar privilegiado al Estado, pues éste une la voluntad subjetiva y la voluntad razonadora o global:

\footnotetext{
Ell Estadb es trasunto de la idea divina tal cono se manifiesta en la tierra. Por lo mismo viene a ser el elemento compositivo más claramente definidb en la historia universal, y en el aal dotiene la libertad su forma dojetiva para ser disfntada...

Al constituir el Estado o la patria una commidad de la existencia, y al scmeterse la voluntad subjetiva del hombre a las leyes desaparece la antítesis entre libertad y necesidad. (Hegel, 1976: 69) .
}

Por cierto, Hegel critica la concepción que afirma que el hombre es libre por naturaleza y que la sociedad y el Estado limitan su libertad natural, pues suponer una libertad natural no tiene ninguna validez histórica, ya que la libertad se adquiere y se conquista. Ell principio de la voluntad individual no puede ser base de la libertad en el Estado, la libertad no puede tener por principio la voluntad subjetiva y la arbitrariedad. 
Para terminar de referirnos a Hegel, notemos su determinismo histórico en el siguiente párrafo:

El principio de la evolución contiene el supuesto de que una determinación intrínseca se halla latente en el fando de la vida y proara su tendencia variante. Esta determinación formal es el espíritu que ha convertido a la historia universal en un escenario y en el campo de su realización. No es algo que se mezcle en el fuego externo de las casualidades, sino que constituye el factor determinante absoluto y que aprovecha lo que es casual para sus designios. (Hegel, 1976: 78-79) .

Marx y Engels (pensadores influenciados por el hegelianismo, pero críticos de él en relación a su idealismo) consideraron que la historia es, fundamentalmente, la historia de la lucha de clases. La historia tiene una meta, un punto culminante: el comunismo. El comunismo es el momento final en que se superarán los antagonismos de clase; vale decir, ya no habrá lucha de clases, por tanto, ya no habrá Estado, ya que éste es el gran defensor y representante de la clase dominante. con el commismo se termina la pre-historia de la humanidad (la historia de la lucha de clases) y se inicia la verdadera historia humana. En el comunismo no existirá división del trabajo y el hombre podrá desarrollar todos sus potencialidades.

Aunque el planteamiento futurista de Marx y Engels tenía sentido en el siglo XIX, hoy comprendemos que sencillamente es errado. El incremento de las fuerzas productivas no ha generado un poder que en bloque choque con la gran burguesía internacional y termine con la última relación de producción histórica. Por el contrario, este desarrollo ha multiplicado exponencialmente el poder industrial, comercial, financiero, militar, tecnológico, informático y en las commicaciones de lo que podríamos todavía considerar como la gran burguesía internacional. ¿Alguien, seriamente, puede pensar hoy que en el futuro va a cambiar la división del trabajo o que el proletariado va a liberar a la humanidad?

En Marx y Engels hay una buena dosis de determinismo histórico, posición que se observa, por ejemplo, en La Ideología Alemana: "Para nosotros, el comunismo no es un estado que debe implantarse, un ideal al que haya de sujetar la realidad. Nosotros llamamos comunismo al movimiento real que amula y supera el estado de cosas actual" (Marx 
y Engels, 1974: 37). Pero hay que reconocer en estos pensadores su agudeza para descubrir el poder del capital y el imperio mundial que ya establecía la burguesía, tal como lo exponen en el Manifiesto:

\begin{abstract}
Merced al rápido perfeccionamiento de los instrumentos de producción y al constante progreso de los medios de commicación, la burguesía arrastra a la corriente de la civilización a todas las naciones, hasta a las más bárbaras; los bajos precios de sus mercancías constituyen la artillería pesada que dernuma todas las murallas de china y hace capitular a los bárbaros más fanáticamente hostiles a los extranjeros. Obliga a todas las naciones, si no quieren sucumbir, a adoptar el modo burgués de producción, las constriñe a introducir la llamada civilización, es decir, a hacerse burgueses. En una palabra, se forja un mundo a su imagen y semejanza. (Marx y Engels 1968: 36) .
\end{abstract}

Marx, además, logra otro punto a su favor cuando en El dieciocho Brumario de Luis Bonaparte hace notar que: "Los hombres hacen su propia historia, pero no la hacen a su libre arbitrio, bajo circunstancias elegidas por ellos mi.smos, sino bajo aquellas circunstancias con que se encuentran directamente, que existen y les han sido legadas por el pasado". (Marx y Engels 1968: 95, s.n.) . De esta manera, Marx señala la presencia de otros factores ajenos a la voluntad y a la libertad del individuo, y que deben tenerse en cuenta en la comprensión de la historia; lo que constituye una de las mejores críticas que se puede hacer a una intenpretación individualista o liberal de la historia.

En 1874, Nietzsche (1949) escribe "De la utilidad y de los inconvenientes de los estudios históricos para la vida" . En este escrito se presenta el para qué de la historiografía, el sentido de la historia en sentido subjetivo. Se tiene necesidad de la historiografía para vivir y obrar y no simplemente para conocer: "la historia, en cuanto es puesta al servicio de la vida, se encuentra al servicio de una potencia nohistórica" (Nietzsche 1949: 97) . Con esto se refiere Nietzsche al arte, a la fuerza de poder olvidar y al poder encerrarse en un horizonte limitado. La historia pertenece al activo y al pooleroso, a quien participa en una gran lucha y no encuentra maestros en el presente; el conocimiento del pasado sólo es deseable en cuanto esté al servicio del presente. 
Mención aparte merece la crítica de Nietzsche a Hegel, que es una crítica a futuro, a quienes hablan del fin de la historia:

... para Hegel, el punto allminante y el punto final del proceso universal coincidirían con su propia existencia berlinesa. Hegel habría debido afirmar así mi.smo que todas las cosas que vinieron detrás de él no deberían ser consideradas exactamente sino como una resonancia musical del rondó universal, más exactamente aún, como algo superfluo; pero no ha afirmado esto. Por el contrario, ha implantadb en las generaciones penetradas de su doctrina esa admiración por "el poder de la historia" que, prácticamente, se transforma en cada momento en una admiración del éxito completamente desmudo y que conduce a la idolatría de los hechos (...) Si cada hecho oculta en sí una necesidad racional, si todo acontecimiento es la victoria de la lógica o de la "idea", no nos queda más que arrodillamos y acatar así todas las formas del "éxito" (Nietzsche 1949: 146) .

Pero, sentencia finalmente Nietzsche: "el hecho es siempre estúpido", es decir, el hecho no se explica por sí mismo, requiere de un intérprete.

Habiendo criticado a Hegel, Nietzsche no se podía eximir de criticar al "objetivismo histórico". Así denuncia la supuesta "objetividad" como el hábito de medir las opiniones y las acciones pasadas por las opiniones corrientes en el momento que los historiadores "objetivos" escriben, consistiendo de esta manera su trabajo en la adaptación del pasado a la trivialidadactual.

Pero Nietzsche también se refiere a lo dbjetivo en su significación suprema y lo vincula al azar y al hombre superior y experimentado, lo que indica que el pasado es palabra de oráculo y solo se le comprende si se es intérprete del presente y constructor del porvenir. Lo dojetivo no excluye la ilusión; al contrario, debe encerrar una ilusión; la historia requiere de una aureola de misterio, todo pueblo que quiere llegar a la madurez requiere de ilusiones protectoras. El mudo marcha, pero el estado ideal no caerá del cielo: es preciso conquistarlo en la lucha.

La esperanza de Nietzsche no es que el curso de los acontecimientos lleve a lo mejor, menos en el siglo XIX, cuando la lucha por el poder y el avance de las masas y el socialismo eran evidentes; su esperanza está depositada en el gran individuo, no en el que continúa el proceso histórico (la marcha de los acontecimientos), sino en quien es una 
especie de puente sobre el sombrío torrente del porvenir. El gran individuo vive fuera del tiempo, es supra-histórico, esto es, desvía su mirada del devenir y la dirige hacia lo que da a la existencia un carácter de etemidad y de identidad. A la historia le incumbe la tarea de meterse entre estos individuos, el dar continuo impulso a la creación de los grandes hombres. El fin de la humanidad solo puede alcanzarse en sus tipos más elevados.

Nietzsche acepta en alguna medida, como otros pensadores, que el egoísmo (ya sea de los individuos, de los grupos o las masas) ha sido la palanca de los movimientos históricos, pero especifica lo siguiente:

Decretamos que el egoísmo debe ser nuestro dios. Con esta nueva fe nos disponemos, sindisimular nuestras intenciones, a edificar la historia futura sobre el egoísmo, exigiendo solamente que sea un egoísmo sabio (...) . Este estudio ha permitido aprender que al Estado le inambe una misión especial en este sistema universal de egoísmo que se quiere fundar. El Estado debe convertirse en patrón de todos los egoísmos sabios para protegerlos, con su poder militar y policíaco, contra los excesos del egoísmo poco sabio. (Nietzsche 1949: 158) .

¿Y qué del papel de las masas? Nietzsche es totalmente contrario a quienes escriben la historia "desde el punto de vista de las masas". Éstas son malas imitadoras de los grandes hombres, son la resistencia con la que se encuentran estos hombres superiores y son instrumentos en manos de los poderosos. En la historia, lo único importante son los grandes individuos, su egoísmo, sus decisiones, sus acciones y metas.

En el siglo XX, es de destacar la propuesta de Karl Popper (1995) . Popper es un liberal, en el más estricto sentido de la palabra y, como tal, cree en el individuo; no en el gran individuo, sino en los individuas commes y corrientes.

Para Popper sólo hay interpretaciones de la historia y ninguna de éstas es definitiva. Preguntas como: "¿Por qué caminos vamos? o ¿qué direcciones y tendencias persigue nuestro tiempo?" (Popper 1995: 160) son planteamientos historicistas, en el sentido que utiliza Popper la palabra "historicista" : se trata de una interpretación supersticiosa que viene desde la antigüedad y que hace profecías históricas. A la pregunta de si tiene un sentido la historia universal, la respuesta de Popper es: "la historia universal no tiene ningún sentido" ; además, no existe 
ninguna historia universal, sino "un ilimitado número de historias que se refieren a todos los aspectos posibles de la vida humana". Lo que ha ocurrido es que se ha elevado a categoría de historia universal, la historia del poder político, pero esto constituye una afrenta para la humanidad, pues esta historia es la historia del crimen nacional e intemacional, y del asesinato en masa.

Somos nosotros (los individuos) los responsables de la historia; solo nuestra conciencia puede jugar a ser juez de nuestros actos, no el éxito que se tenga en el mundo. La historia no tiene ninguna finalidad, pero podemos imponerle una finalidad; la historia no tiene ningún sentido, pero podemos otorgarle un sentido. Popper insistirá en estas ideas, señalando que: "Ni la naturaleza ni la historia nos pueden decir lo que debemos hacer. (...) Somos nosotros quienes introducimos finalidady sentidb en la naturaleza y en la historia. (...) Las instituciones humanas, como el Estado, no son racionales, pero podemos decidimos a luchar para hacerlas més racionales". (Popper 1995: 172). Ell progreso, el avance hacia un fin determinado, tampoco es algo que dependa de la historia, sino de los individuos humanos, y el progreso se producirá en la medida en que se defiendan y fortalezcan las instituciones democráticas de las que depende la libertad.

Terminamos esta revisión de posiciones interpretativas de la historia, con la interpretación de otro defensor de la democracia liberal, el ideólogo contemporáneo del fin de la historia: Francis Fukuyama. Fukuryama hace notar que, en el curso de la historia de los diferentes regímenes que han aparecido, la única forma que ha sobrevivido hasta fines del siglo XX ha sido la democracia liberal. La idea liberal ha resultado victoriosa en la medida en que no hay ideología con pretensiones de universalidad que pueda competir hoy con ella. Tan evidente es su éxito, que hasta los no demócratas tienen que expresarse en el lenguaje de la democracia para justificar su discrepancia. Ello le lleva a suponer que hay un proceso que responde a una tendencia en la evolución de las sociedades humanas que se dirige hacia la democracia liberal. Los principios en los que se basa ésta (libertad e igualdad) no pueden ser accidentes o resultado de prejuicios etnocéntricos, sino que tienen que ver con la misma naturaleza humana. 
La cuestión de la existencia de la historia universal y de su racionalidad no es nueva:

... Desde el comienzo, las tentativas más serias y sistemáticas de escribir historias universales consideraron como eje de la historia el desarrollo de la libertad. La historia no era una ciega concatenación de acontecimientos, sino un conjunto con sentidb en el arl se desarrollaron y compitieron las ideas humanas referentes a la naturaleza de un orden social y político justo. (Fuklyama 1996: 89) .

Fukuyama considera a Hegel como el filósofo de la libertad y a la dialéctica hegeliana como una discusión entre dos, en la que prevalece el lado que se contradice menos a sí mismo; y si ambos se contradicen por igual, surge una tercera posición superadora, de manera que "se puede describir la historia como un diálogo entre sociedades, en el cual aquellas con graves contradicciones intemas fracasan y se ven sucedidas por otras que logran superar esas contradicciones" (Fukuyama 1996: 102) . Cuando Hegel declaró que la historia había terminado con la batalla de Jena, en 1806, significaba que "los principios de libertad e igualdad subyacentes en el Estado liberal moderno habían sido descubiertos y aplicados en los países más adelantados, y que no existían principios o formas altemativas superiores al liberalismo". (Fukuyama 1996: 106) .

Entonces, ¿cuál es el fin de la historia? Para nosotros la pregunta tiene dos respuestas. La historia como conjunto de acontecimientos, como historia "en sí", no tiene ningún fin. En cambio, la historia como historiografía, como efectos buscados o soluciones, sí tiene un fin. Como proponía Nietzsche, la narración del pasado debe estar en función del presente y del futuro, de las tareas y metas que -como comunidad o conjunto de comunidades- se establezcan en relación a las propias necesidades; éste debe ser el punto de partida. Lo segundo es ver cómo estas necesidades pueden ser satisfechas en relación al medio, sin llegar al extremo de dejar de ser nosotros mismos, aunque nuestra identidad sea de lo más precaria.

En la situación presente, se plantea a los países periféricos, la disyuntiva entre el progreso prometido por Occidente y la resistencia a ese progreso. Cuando nos referimos a "Occidente" seguramente pecamos de imprecisos, pues este concepto se refiere a muchas cosas: 
cristianismo, modas, música, televisión, bebidas gaseosas, comidas rápidas, derechos humanos y, para no abundar más en cosas en las que somos occidentales o estamos influenciados por Occidente, (reconozcamos que hasta el idioma que empleamos es occidental) sin embargo, específicamente, me refiero a las dos grandes pinzas de la tenaza occidental) al sistema económico capitalista con su doctrina del mercado libre y a la democracia liberal con sus instituciones. No puede tampoco dejarse de ver en ambas fuerzas la presencia dominante del poderío norteamericano.

La altemativa a Oocidente es la resistencia a su poder. Esta resistencia hasta ahora es básicamente reactiva; es decir, no ha logrado construir una ideología altemativa. Sin embargo, aparecen como puntas de lanza el movimiento zapatista de México que se alzó en rebeldía en Chiapas, el mismo día que se inauguraba el NAFTA (01-01-94), las protestas de los indígenas campesinos ecuatorianos que expulsaron a Jamil Mahuad del poder y el movimiento de Felipe Quispe, que ha obligado a Sánchez de Losada a huir y exiliarse en $\mathrm{EE}$. UU. No creo que una verdadera altemativa sea de corte folclórico e inspirada románticamente en el pasado, pero sí reconozco en estos indicadores el malestar frente al sistema y la lucha por sobrevivir. Una verdadera altemativa debería, como primera tarea, tomar conciencia de nuestras necesidades y luego estudiar cómo éstas pueden satisfacerse en las condiciones que el dominio occidental nos impone.

Occidente ha logrado que su sistema económico se afirme y que el mundo sea efectivamente uno solo, es decir, con un solo sistema económico. Con respecto a esta situación y en las condiciones actuales, no queda, en la práctica, sino adaptarse, que no es lo mismo que subordinarse ${ }^{2}$. Pero Occidente busca una segunda gran victoria, que es lo que más conviene al mantenimiento de su hegemonía, imponer como único sistema político la democracia liberal y sus instituciones y de este modo hacer que los gobernantes de los países en vías de desarrollo piensen y hablen como ellos.

Levantar una verdadera y nueva altemativa no es nada fácil, pues -de surgir-tendría que combatir en dos frentes para afirmarse: Contra la ideología occidental y contra las ideologías retrógradas que se nutren, o de un pasado mítico o de un fundamentalismo marxista- 
estatista. Una nueva alternativa no puede abogar por el burocratismo y el engrosamiento de un Estado corporativista e ineficiente.

\section{Notas}

1 Este texto es una versión, ligeramente modificada, de la ponencia homónima presentada por el autor en el XV Congreso Interamericano de Filosofía y II Congreso Iberoamericano de Filosofía, realizado por la PUC del Perú, del 12 al 16 de enero de 2004.

2 La planificación socialista y sus gestores (los privilegiados burócratas del Partido camuista) como experimento económico han probado, suficientemente, su fracaso. Los chinos han tenido la habilidad de preservar sus avances sociales, introduciendo el capitalismo, pero cuidándose de no ceder demasiado en lo político. La autarquía no es ninguna alternativa, es como exponer a Occidente una llamativa burbuja de jabón, bastaría un pinchazo para terminar con la aventura.

\section{Referencias bibliográficas}

COLHTNGOOD, R.G. (1952) : Idea de la historia. F.C.E. México, 1965.

FUKUYAMA, Francis (1992) : El fin de la Historia y el último hambre. Planeta. Buenos Aires, 1996.

HEGH, G.W.F. (1976) : Filosofía de la Historia. Claridad. Buenos Aires.

KAHIHR, Eridk (1966) : ¿Quées la historia? F.C.E. Néxico.

IÖNIIH, Karl (1956) : Ell sentidb de la Historia. Aguilar. Madrid, 1973.

MARX Y ENGEIS (1974) : La Ideología Alemana. Pueblos Unidos y Grijalbo. MbntevideoBarcelona.

MARX Y ENGFIS (1968) : Obras Escogidas. Progreso. Mbscú.

NIEIZSCHE, F. (1949) : Consideraciones intempestivas 1873-1875 [Obras Completas, tomo II] Aguilar. Buenas Aires.

POPPER, Karl (1994) : La responsabi 7idad de vivir. Escritos sobre política, historia y conocimiento. Paidós. Barcelona, 1995. 